\title{
OS DIREITOS HUMANOS COMO EFETIVAÇÃO DA JUSTIÇA EM RICOEUR
}

\author{
HUMAN RIGHTS AS IMPLEMENTATION OF JUSTICE IN RICOEUR
}

\author{
Marcella Marques dos Santos Cerilo \\ Bacharel em Direito pela Universidade do Estado da Bahia (UNEB) \\ Universidade do Estado da Bahia (UNEB) \\ Salvador/BA. Brasil. \\ marcella_cerilo@hotmail.com
}

\author{
Viviane Almeida Vieira \\ Mestre em Ecologia Humana e Gestão Socioambiental \\ pela Universidade do Estado da Bahia (UNEB) \\ Universidade do Estado da Bahia (UNEB) \\ Salvador/BA. Brasil. \\ vivialmeidavieira@gmail.com \\ Elton Moreira Quadros \\ Doutor em Memória: Linguagem e Sociedade (UESB) \\ Universidade do Estado da Bahia (UNEB) \\ Salvador/BA. Brasil. \\ eltonquadros@yahoo.com.br
}

\begin{abstract}
Resumo: Consideramos que a reflexão de Paul Ricoeur sobre a justiça pode ser um importante caminho para a demanda acerca de tornar os Direitos Humanos (DH) socialmente relevantes. A concepção de justiça de Ricoeur está interligada com as prerrogativas da norma moral e em diálogo com a Declaração Universal dos Direitos Humanos (DUDH), especialmente na reflexão que propomos a partir do método hermenêutico-fenomenológico ricoeuriano sobre os DH como o critério balizador para a efetivação da justiça. Destacamos aqui três pontos fundamentais do pensamento ricoeuriano: a igualdade no sentido de uma justiça distributiva, o reconhecimento jurídico, tendo em vista a acolhida da alteridade independentemente das concepções sociais hegemônicas, e, por fim, a efetivação de instituições justas como o caminho para a garantia e proteção dos DH. Portanto, ao unirmos esses três fundamentos, percebemos a relação que Ricoeur estabelece entre a Justiça e os DH, bem como a importância da reflexão jus-filosófica para lançar novas luzes quanto à busca pela efetividade dos DH, encontrada na possibilidade real de alcançar a justiça para todos os seres humanos.
\end{abstract}

Palavras-chave: Ética. Igualdade. Instituições justas. Reconhecimento jurídico.

Abstract: We consider that Paul Ricoeur's reflection on justice can be an important way to the demand about making Human Rights (HR) socially relevant. Ricoeur's conception of justice is interconnected with the prerogatives of the moral standards and in dialogue with the Universal Declaration of Human Rights (UDHR), especially in the reflection we propose from the Ricoeurian hermeneutic-phenomenological method on HR as the delimit criterion for the effective implementation of justice. Here we highlight three fundamental points of ricoeurian thinking: equality towards distributive justice, legal recognition, in view of the acceptance of alterity independently of hegemonic social conceptions and, finally, the implementation of just institutions as the way to guarantee and protect HR. Therefore, by uniting these three principles, we realize the correlation that Ricoeur establishes between justice and HR, as well as the importance of jus-philosophical reflection to shed new light on the search for the effectiveness of HR, found in the real possibility of achieving justice for all human beings.

Keywords: Ethics. Equality. Fair institutions. Legal recognition.

\section{Para citar este artigo}

ABNT NBR 6023:2018

CERILO, Marcella Marques dos Santos; VIEIRA, Viviane Almeida; QUADROS, Elton Moreira. Os direitos humanos como efetivação da justiça em Ricoeur. Prisma Jurídico, São Paulo, v. 19, n. 2, p. 304-318, jul./dez. 2020. http://doi.org/10.5585/prismaj.v19n2.13352. 
CERILO, Marcella Marques dos Santos; VIEIRA, Viviane Almeida; QUADROS, Elton Moreira. Os direitos humanos como efetivação da justiça em Ricoeur e da CERILO, Marcella Marques dos Santos; VIEIRA, Viviane Almeida; QUADROS, Elton Moreira. Os direitos humanos como efetivação da justiça em Ricoeur

\section{Introdução}

Com relação à justiça, Ricoeur afirma: “a justiça é a primeira virtude das instituições sociais, assim como a verdade é a primeira virtude dos sistemas de pensamento" (RICOEUR, 2008, p. 30). A partir disso, o autor passa a se preocupar com relação ao direito que está na prática do juízo que interpreta o direito em situação. Assim, o juízo do magistrado e de cada cidadão é, para ele, o cenário cotidiano do desejo de justiça. Logo, a procura da justiça vem desde "as experiências infantis de espanto ou de indignação perante a injustiça, as partilhas desiguais, as promessas traídas, as punições ou as retribuições desproporcionais” (ABEL, 2002, p. 12). Nesse aspecto, essa procura pela justiça já contém, em si, a justiça distributiva.

Nesse sentido, refletimos acerca dos Direitos Humanos como efetivação da justiça, destacando três fundamentos: 1) a igualdade como um dos princípios basilares dos Direitos Humanos e tão importante para composição da justiça; 2) o reconhecimento jurídico como segundo fundamento da composição da justiça sob a mediação dos Direitos Humanos, tendo em vista o reconhecimento mútuo, através da identidade, no pensamento jusfilosófico de Ricoeur, no qual o reconhecimento jurídico se comunica com a solicitude (tríade ética de Ricoeur $\left.^{1}\right)$; 3) por fim, o terceiro fundamento, que são as instituições justas como meio de efetivação e aplicação dos direitos humanos.

No que tange ao método hermenêutico-fenomenológico, a abordagem de Ricoeur parte da efetuação da linguagem como discurso. Ricoeur defende que todo discurso surge como um evento realizado temporalmente e no presente, pois o caráter do evento se vincula à pessoa daquele que fala. $\mathrm{O}$ evento consiste no fato de alguém falar, de alguém se exprimir tomando a palavra. O discurso é sempre discurso a respeito de algo, refere-se sempre ao mundo que pretende descrever, exprimir ou representar para alguém. Nessa perspectiva, o discurso possui um mundo criado, interpretado, que, na medida do diálogo com o outro, estabelece pontes para a comunicação (MORAES, 2005).

Assim, pensando em que medida a busca pelos DH pode contribuir para a efetivação da justiça e como podem se complementar, destacamos que é a partir daqui, desse ponto ainda pouco explorado no debate jurídico, que surge o desejo de expor essa relação através da perspectiva ética e moral, perpassando pela igualdade, reconhecimento jurídico e instituições justas, com um olhar que recoloca a importância de pensar os DH e a justiça por uma ótica jusfilosófica.

\footnotetext{
${ }^{1}$ Ricoeur, em sua "pequena ética", articula numa tríade, na qual o si mesmo, o outro próximo e o outro distante são igualmente honrados: viver bem, com e para os outros, em instituições justas (RICOEUR, 2008b).
} 
CERILO, Marcella Marques dos Santos; VIEIRA, Viviane Almeida; QUADROS, Elton Moreira. Os direitos humanos como efetivação da justiça em Ricoeur e da CERILO, Marcella Marques dos Santos; VIEIRA, Viviane Almeida; QUADROS, Elton Moreira. Os direitos humanos como efetivação da justiça em Ricoeur

Portanto, é pela questão da injustiça ou da aplicabilidade injusta das distribuições que Ricoeur percebe a necessidade de buscar e compreender o sentido de justiça. Os pontos fortes a serem discutidos aqui são a instituição como ponto de aplicação da justiça e a igualdade como conteúdo ético do sentido de justiça e dos direitos humanos. Desta forma, a estima e o respeito são categorias essenciais para a compreensão do papel ético, moral e jurídico do reconhecimento da igual e universal dignidade dos seres humanos.

\section{Breve esboço histórico dos direitos humanos e a igualdade}

A Declaração Universal dos Direitos Humanos (1948), em seu preâmbulo, reconhece que todos possuem direitos iguais, de forma inalienável, intransferível: "considerando que o reconhecimento da dignidade inerente a todos os membros da família humana e de seus direitos iguais e inalienáveis é o fundamento da liberdade, da justiça e da paz no mundo" (ONU, 1948).

Nesse sentido, o início das discussões acerca da igualdade se desenvolve mais fortemente a partir dos conflitos existentes no século XVII até a metade do século XIX, criados pelo capitalismo, além de se poder incluir, nesse momento político, o socialismo, que encontra seus fundamentos nos movimentos mais radicais da Revolução Francesa, os quais queriam não somente a realização da liberdade, mas também da igualdade (TOSI, 2002).

Dessa forma, a Revolução Francesa reivindicava a igualdade dos cidadãos diante da lei, mas o capitalismo estava criando novas e grandes desigualdades econômicas e sociais, e o Estado nada fazia para colocar um fim a essa situação.

Assim, os movimentos revolucionários de 1848 constituem um acontecimento primordial na história dos direitos humanos, porque conseguem, pela primeira vez, que o conceito de "direitos sociais" seja acolhido na Constituição Francesa. Já nas Declarações posteriores à de 1789, aparecem, de forma mais explícita, quais são os direitos sociais, o que gera a inclusão da liberdade e da igualdade com maior efetividade na Constituição Francesa de 1848 (TOSI, 2002).

Com isso, de fato, foi através das lutas dos movimentos operários e populares que os direitos sociais, sobretudo após a Segunda Guerra Mundial, começam a ser colocados nas Cartas Constitucionais e postos em prática de forma efetiva, criando, assim, o chamado "Estado do Bem-estar Social" nos países capitalistas.

Vale destacar aqui que o processo de liberdade e igualdade não foi (e não é ainda) tão simples como pareceu ser ao descrevermos um breve esboço das lutas para se chegar às discussões acerca dos direitos fundamentais (igualdade, liberdade etc.). Na verdade, "nunca foi 
CERILO, Marcella Marques dos Santos; VIEIRA, Viviane Almeida; QUADROS, Elton Moreira. Os direitos humanos como efetivação da justiça em Ricoeur e da CERILO, Marcella Marques dos Santos; VIEIRA, Viviane Almeida; QUADROS, Elton Moreira. Os direitos humanos como efetivação da justiça em Ricoeur

fácil colocar em prática, ao mesmo tempo, os direitos de liberdade e os direitos de igualdade" (TOSI, 2002, p. 25).

É a partir daí que, em 1945, a ONU (Organização das Nações Unidas), com o fito de evitar uma terceira guerra mundial e com o objetivo de promover a paz entre as nações, considerou que a promoção dos direitos fundamentais era a chave principal para uma paz duradoura. Por isso, após alguns anos, um dos primeiros atos da Assembleia das Nações Unidas foi a proclamação, em 1948, de uma Declaração Universal dos Direitos Humanos, cujo primeiro e principal artigo dispõe que "todas as pessoas nascem livres e iguais em dignidade e em direitos. São dotadas de razão e de consciência e devem agir em relação umas às outras com espírito de fraternidade (ONU, 1948)".

Esse artigo da Declaração Universal dos Direitos Humanos nos traz à recordação os direitos de primeira geração, que incluem os direitos civis e políticos, além de todas as liberdades e igualdades perante a lei. No próximo tópico, passamos a discutir a igualdade como princípio dos Direitos Humanos e da Justiça.

\section{A igualdade como princípio basilar dos direitos humanos e da justiça em Ricoeur}

Diante do que até aqui fora exposto, Ricoeur, em sua abordagem do justo, relata que "a justiça é o conjunto dos processos que permitem organizar os conflitos entre as intenções, para que o conflito permaneça viável” (RICOEUR, 2008a, p. 41). É aqui que entra a deontologia como regra, que não se confunde com a regra jurídica (a lei), mas se trata de algo mais forte do que a legalidade, que é o princípio da reciprocidade, que esclarece os contextos mais vastos ou secretos, deficientemente representados nos processos jurídicos ou democráticos (ABEL, 2002).

Assim, para melhor explicar as regras do princípio da reciprocidade, Abel (2002) expõe que o direito positivo, através de suas regras, não se aplica nem ao infradireito como indiferença, a distribuição arbitrária do elogio e da censura, nem ao supradireito, ou seja, as democracias ricas que parecem tolerar bem e mesmo tirar partido das sociedades não democráticas da sua periferia, denominadas por ele antagonismos planetários.

Dessa maneira, a regra aplicar-se-á às relações entre os sujeitos, às relações sociais e às instituições. Nesse sentido, o entendimento de Ricoeur é que: 


\begin{abstract}
A ocasião para a violência, para não dizer a tendência para a violência, reside no poder exercido sobre uma vontade por uma vontade. [...] o poder-sobre, implantado na dissimetria inicial entre o que um faz e o que é feito ao outro - por outras palavras, o que este outro sofre -, pode ser tomado, por excelência, pela ocasião do mal da violência. O sentido descendente faz passar facilmente da influência, forma suave do poder-sobre, à tortura, forma extrema do abuso. No próprio domínio da violência física, enquanto utilização abusiva da força contra outrem, as imagens do mal são inúmeras, desde a simples utilização da ameaça, passando por todos os níveis do constrangimento, até ao homicídio. Sob estas formas diversas, a violência equivale à diminuição ou a destruição do poder-agir de outrem. Mas pior ainda: na tortura, o que o executor procura atingir e por vezes - enfim - consegue destruir, é a auto-estima [sic] da sua vítima, estima que a passagem pela norma elevou à categoria de respeito por si mesmo (RICOEUR, 2014, p. 60).
\end{abstract}

Na citação acima, Ricoeur expõe que o equilíbrio dos deveres e dos direitos de cada um pressupõe um sujeito capaz de estima, mas se desenvolve no plano de uma moral do sujeito capaz de respeito, antes de passar ao nível dos processos políticos e jurídicos (RICOEUR, 2008a).

Abel (2002, p. 74) conceitua o sujeito capaz de respeito como "a capacidade de tratar outrem como a si próprio e a si próprio como outrem ou em poucas palavras, para lá dos processos da legalidade democrática (isto é, do conjunto das regras de direito que permitem a negociação dos conflitos)". Ricoeur coloca o motivo dessa vertente normativa do justo como "não exerças o poder sobre outrem, de tal forma que fiques sem poder sobre ti mesmo" (RICOEUR, 2014, p. 61).

As diferentes formulações examinadas por Ricoeur sobre a regra da reciprocidade, sendo analisada aqui como igualdade, dão, antes de mais nada, lugar à invenção moral, uma vez que elas interditam o sujeito de fazer a outrem o que ele não gostaria de que lhe fizessem, o que levaria a crer que nunca usaria de violência contra o outro (ABEL, 2002).

As fórmulas positivas da reciprocidade/igualdade têm como vantagem que estas orientam a moral para o respeito benevolente pelas pessoas e não para o respeito abstrato da lei (RICOEUR, 2014).

Desta forma, o fundamento moral desta concepção é que "a ideia de que qualquer um tem o direito de utilizar as justificações que eu próprio me autorizo" (ABEL, 2002, p. 75), ou seja, as minhas justificações, as minhas normas ou as minhas intenções, o que Kant designa como "máximas da minha vontade", que significa que são perfeitamente particulares e ligadas a um contexto (RICOEUR, 2008a), devem ser sempre universalizáveis, devendo poder atribuílas a qualquer um dos meus parceiros ou adversários.

Então, Abel (2002) explica que o imperativo de não contradição das minhas máximas é mais do que formal, em outras palavras, ele implica, igualmente, o não fazer o contrário do que 
CERILO, Marcella Marques dos Santos; VIEIRA, Viviane Almeida; QUADROS, EIton Moreira. Os direitos humanos como efetivação da justiça em Ricoeur e da CERILO, Marcella Marques dos Santos; VIEIRA, Viviane Almeida; QUADROS, Elton Moreira. Os direitos humanos como efetivação da justiça em Ricoeur

se diz. É essa abordagem filosófica, explica Abel (2002, p. 75), que "Kant chama de autonomia, ou seja, a capacidade de se ser autor da lei (aplicável a qualquer um) à qual se obedece”. Assim, o sujeito mantém perante outrem certa coerência moral para além das variações dos seus desejos e interesses.

Com isso, percebemos que a igualdade é primordial para os Direitos Humanos, bem como para a justiça em Ricoeur, uma vez que esta perpassa pela estima de ser componente da visada ética, com o desejo de aspiração de vida boa, de uma plena realização pessoal com e para os outros, de maneira igual.

Passamos agora para a análise do próximo tópico de caráter importante para a efetivação da justiça por meio dos direitos humanos, que é o reconhecimento jurídico, ou seja, o reconhecimento de si e do outro, diante da estima do outro, ou como chamamos, a solicitude.

\section{O reconhecimento jurídico em Ricoeur}

Como vimos no tópico anterior, a igualdade é parte fundamental dos direitos humanos e, com isso, passa a ser uma das peças principais para a efetivação da justiça. Desse modo, com o entendimento da igualdade como fundamento para justiça, vamos agora ao segundo componente fundamental, que é o reconhecimento jurídico - marcado no plano moral por Ricoeur - da solicitude, que se compara aqui com o reconhecimento.

Para Quadros (2017), o reconhecimento mútuo é uma capacidade dada aos humanos pela via simbólica. Nesse sentido, Ricoeur coloca que

[...] a luta pelo reconhecimento se perderia na consciência infeliz se não fosse dada aos humanos a possibilidade de ter acesso a uma experiência efetiva, embora simbólica, de reconhecimento mútuo, com base no modelo do dom cerimonial recíproco. (RICOEUR, 2008a, p. 165).

Assim, o reconhecimento mútuo e o reconhecimento de si nos remetem ao sujeito capaz, que acaba revelando as suas incapacidades e, portanto, a sua condição não é um dado pronto e acabado, mas uma tarefa que se dá através de mediações, de relações entre o eu e o mundo e do eu e o outro.

Dessa forma, quando partimos de uma análise do reconhecimento baseado na identidade, percebemos que excluímos o outro em busca de uma afirmação do "eu", mas "quando dermos um passo adiante e tratamos o reconhecimento através da ipseidade, podemos compreender que o mesmo e o outro podem ser, pelo menos, afetados mutuamente" (QUADROS, 2017, p. 145). 
CERILO, Marcella Marques dos Santos; VIEIRA, Viviane Almeida; QUADROS, Elton Moreira. Os direitos humanos como efetivação da justiça em Ricoeur e da CERILO, Marcella Marques dos Santos; VIEIRA, Viviane Almeida; QUADROS, Elton Moreira. Os direitos humanos como efetivação da justiça em Ricoeur

O posicionamento de Ricoeur se encontra no trajeto aberto pelo ato soberano do reconhecimento/identificação, ou seja, "o reconhecimento de si, em virtude dessa última dialética [identidade e alteridade], abre também o caminho para a problemática do ser reconhecido, implicado pela exigência de reconhecimento mútuo [...]” (RICOEUR, 2006, p. 109). Nessa perspectiva, o reconhecimento de si mesmo ocupa para Ricoeur um lugar mediano nesse longo trajeto em razão precisamente dos traços de alteridade que, no momento da autodesignação do sujeito, das capacidades que indica a gramática do "eu posso", associam-se aos outros dois traços: "a caracterização da ação pelas capacidades em que elas constituem o efetuar-se, e o desvio da reflexão pelo lado objetal das experiências consideradas" (RICOEUR, 2006, p. 109).

O reconhecimento no plano jurídico está marcado por uma resposta no plano moral de Hobbes. Por isso, "há um peso na ideia de crime e no direito como o local de reconhecimento, na figura básica do ser-reconhecido. Nesse território, a troca constitui a marca dessa forma de reconhecimento" (QUADROS, 2017, p. 155).

Para Quadros, Ricoeur entende que o crime é um dos mediadores entre a vontade individual e a vontade universal, no entanto,

\footnotetext{
Diante da noção de direitos humanos e, por consequência, uma ideia de que é possível uma certa (luta por) oportunidades iguais, Ricoeur acredita que ainda é possível manter essa discussão que passa pelo não-reconhecimento ligada à instituição do direito. (QUADROS, 2017, p. 155).
}

Nesse sentido, ter direitos e compreender-se como portador de direitos é também reconhecer que temos obrigações normativas para com o outro e, portanto, o objetivo do reconhecimento é duplo: outrem e norma. Com relação à norma, o reconhecimento significa considerar válido, admitir a validade; já com relação à pessoa, reconhecer é identificar cada pessoa enquanto livre e igual a toda outra pessoa (QUADROS, 2017). Não podemos perder de vista que, para Ricoeur “o sentido de justiça, que possui uma dimensão imemorial, como testemunham as tragédias gregas, não se restringe à construção de sistemas jurídicos" (SALLES, 2019, p. 416), por isso, a questão da alteridade está relacionada com o ordenamento jurídico e, somente assim, podemos pensar efetivamente em efetivação da justiça.

Nesse sentido, a Declaração Universal dos Direitos Humanos, em seu preâmbulo, como primeiro ponto em destaque, afirma o reconhecimento da dignidade humana como pessoa detentora de igualdade e liberdade, considerando que o reconhecimento da dignidade é inerente a todos os seres humanos, que são detentores direitos iguais e inalienáveis como fundamento da liberdade, da justiça e da paz no mundo (ONU, 1948). 
CERILO, Marcella Marques dos Santos; VIEIRA, Viviane Almeida; QUADROS, Elton Moreira. Os direitos humanos como efetivação da justiça em Ricoeur e da CERILO, Marcella Marques dos Santos; VIEIRA, Viviane Almeida; QUADROS, Elton Moreira. Os direitos humanos como efetivação da justiça em Ricoeur

Dessa forma, o reconhecimento no sentido jurídico acrescenta, assim, ao reconhecimento de si em termos de capacidade as novas capacidades provenientes da conjunção entre a validade universal da norma e a singularidade das pessoas (QUADROS, 2017).

Esse reconhecimento jurídico consiste, assim, na conexão entre a ampliação da esfera dos direitos reconhecidos às pessoas e o enriquecimento das capacidades que esses sujeitos reconhecem em si mesmos (QUADROS, 2017). Para Ricoeur, "essa ampliação e esse enriquecimento são o produto de lutas que pontuam a inscrição, na história, desses dois processos solidários" (RICOEUR, 2008, p. 168).

Nesse aspecto, poderíamos falar de uma ampliação das capacidades jurídicas da pessoa, chegando ao ponto de podermos falar em direitos subjetivos, que estariam repartidos entre os direitos humanos: os direitos civis, políticos e sociais.

Assim, diante dessa capacidade jurídica da pessoa é que podemos,

Falar da negatividade na figura do reconhecimento, no plano jurídico, a partir do menosprezo relativo - às exigências que uma pessoa pode esperar ver satisfeitas pela sociedade [...] [e] a humilhação relativa à negação de direitos civis ou da exclusão na participação da formação da vontade pública ou do acesso aos bens elementares (RICOEUR, 2008, p. 214).

Então, ao ter o reconhecimento social negado, "há muitas vezes a perda do respeito por si mesmo e, por isso, é preciso - lembrar que os sentimentos negativos são impulsionadores significativos da luta pelo reconhecimento" (QUADROS, 2017, p. 155), pois, como diz Ricoeur, "a indignação constitui a estrutura de transição entre o menosprezo sentido na emoção da irritação e a vontade de se tornar um parceiro na luta pelo reconhecimento" (RICOEUR, 2008, p. 214).

É a partir daí que a noção de responsabilidade ganha o seu espaço, uma vez que abrange a asserção de si e o reconhecimento do direito igual de outrem de contribuir para os avanços do direito e dos direitos (RICOEUR, 2008). Isso significa dizer que não temos somente, a noção do reconhecimento de si e (do) outro, mas a dependência de um em relação ao outro, "a importância do reconhecimento do eu e do nós, especialmente quando nos colocamos no caminho da luta pela dignidade humana" (QUADROS, 2017, p. 166).

Nessa perspectiva, é preciso ter claro que o reconhecimento não nos interessa somente como um dado a ser descrito ou como um percurso que ainda precisa ser desenvolvido, uma vez que possuímos tanto a necessidade de compreendê-lo como de tê-lo em perspectiva, debatendo as suas possibilidades e ampliações (QUADROS, 2017). Assim, é a partir de valores 
CERILO, Marcella Marques dos Santos; VIEIRA, Viviane Almeida; QUADROS, Elton Moreira. Os direitos humanos como efetivação da justiça em Ricoeur e da CERILO, Marcella Marques dos Santos; VIEIRA, Viviane Almeida; QUADROS, Elton Moreira. Os direitos humanos como efetivação da justiça em Ricoeur

e objetivos comuns que os sujeitos avaliam as próprias qualidades para a vida em comum, em relação aos outros.

Dessa maneira, o reconhecimento jurídico aliado com a igualdade faz com que cheguemos ao nosso próximo tópico, o qual trata das instituições justas como intermédio da aplicação dos direitos humanos como meio para efetivar a justiça, perpassando pelo viés filosófico de Ricoeur, uma vez que a conexão entre esses pontos é de suma importância para se destacar a relação existente entre as instituições justas e os Direitos Humanos.

\section{As instituições justas como meio de efetivação dos direitos humanos em Ricoeur}

A igualdade e o reconhecimento jurídico dos direitos humanos se complementam ao ponto em que, para que haja a sua aplicação necessária, faz-se incluir a esses fundamentos as instituições justas, uma vez que "o si mesmo, o outro próximo e outro distante são igualmente honrados, viver bem, com e para os outros em instituições justas" (RICOEUR, 2008b, p. 62).

Nesse tópico, abordamos a questão do processo judicial como ponto de aplicação da justiça e dos Direitos Humanos, porém as instituições justas vão além de papéis, partilhas desiguais e decisões imparciais.

Assim, a Declaração Universal dos Direitos Humanos, em seus artigos $8^{\circ}$ e $10^{\circ}$, garante a todo ser humano o direito a um julgamento justo, por meio de audiência pública com garantias dos seus direitos fundamentais, ou seja, os tribunais nacionais competentes têm o dever de fornecer os remédios efetivos para garantirem o acesso à justiça em plena igualdade, garantindo ainda um tribunal independente e imparcial para decidir os direitos e deveres de todo ser humano (ONU, 1948).

Com relação ao que diz o art. $10^{\circ}$ da DUDH, ou seja, a igualdade de uma audiência ou julgamento por um tribunal independente e imparcial, Ricoeur (2008b) diz, nesse sentido, que a tomada de decisão que norteia a sentença, no âmbito do processo judiciário, vincula-se numa formulação concreta a ideia de justiça que, além de qualquer direito positivo, é do domínio do querer viver bem.

Esse querer viver bem nos lembra de uma das teses da pequena ética de Ricoeur, momento em que a intenção ética se articula numa tríade, na qual "o si mesmo, o outro próximo e o outro distante são igualmente honrados: viver bem, com e para os outros, em instituições justas" (RICOEUR, 2008b, p. 62).

Nesse sentido, Ricoeur coloca que a ética judiciária encontra na vontade de viver em instituições justas a exigência que liga o conjunto das instituições judiciárias à ideia de vida 
CERILO, Marcella Marques dos Santos; VIEIRA, Viviane Almeida; QUADROS, Elton Moreira. Os direitos humanos como efetivação da justiça em Ricoeur e da CERILO, Marcella Marques dos Santos; VIEIRA, Viviane Almeida; QUADROS, Elton Moreira. Os direitos humanos como efetivação da justiça em Ricoeur

boa. Para ele, "é esse querer viver em instituições justas que encontra visibilidade e legibilidade na palavra de justiça proferida pelo juiz na aplicação das normas que, por sua vez, estão no cerne da moralidade privada e pública” (RICOEUR, 2008b, p. 62).

Ricoeur relata que já tinha encontrado o "cada um” em situações exemplares que provocaram sua indignação contra a injustiça desde quando era jovem, sejam em divisões desiguais, promessas não cumpridas e as punições que lhe pareciam sem proporção com a falta cometida, que a seu ver não era merecida, "tantas circunstâncias institucionais, no sentido amplo do termo, onde a justiça se enuncia como distribuição justa" (RICOEUR, 2008a, p. 45).

Nesse ponto, Ricoeur diz que esse "cada um” já se encontrou nas situações exemplares, nas quais nossa indignação se exaltava contra a injustiça: "nas divisões desiguais, descumprimento da palavra dada, retribuições iníquas - circunstâncias essas institucionais, no sentido amplo do termo, em que a justiça se anuncia como distribuição justa" (RICOEUR, 2008a, p. 08).

Assim, a instituição judiciária é "peculiarmente favorável a uma determinação mais rigorosa do cada um segundo a instituição: com a instituição do tribunal, o processo põe em confronto partes que são constituídas como "outras" pelo procedimento judiciário" (RICOEUR, 2008a, p. 09). Melhor dizendo, a instituição se encontra no personagem do juiz, que, quando colocado como terceiro entre as partes do processo, desempenha o papel do terceiro em segundo grau, sendo ele o operador da justa distância que o processo institui entre as partes.

Ricoeur relata, em sua obra O Justo 1, as várias formas de descrever a palavra julgar, ato do juiz nos comandos sentenciais, de grande importância para aplicação dos direitos humanos, da igualdade e de reconhecer o outro como a si mesmo. Nesse sentido, Ricoeur diz que o ato de julgar no sentido judiciário da palavra, e de forma mais fraca, é opinar, expressar uma opinião a respeito de alguma coisa (RICOEUR, 2008a). Num sentido um pouco mais forte,

É avaliar, incluindo aqui um elemento hierárquico que expressa apreciação, aprovação. Já em um grau de força expressa o encontro entre o lado subjetivo e o lado objetivo do julgamento. Lado objetivo: alguém considera uma proposição verdadeira, boa, justa, legal; lado subjetivo: adere a ela (RICOEUR, 2008a, p. 175).

Por último, no nível mais profundo da palavra julgar, "o julgamento procede da conjunção entre entendimento e vontade: o entendimento que considera o verdadeiro e o falso; a vontade que decide" (RICOEUR, 2008a, p. 176). Assim, atingimos o sentido forte da palavra julgar: não só opinar, avaliar, considerar verdadeiro, mas, em última instância, tomar posição (RICOEUR, 2008a). 
CERILO, Marcella Marques dos Santos; VIEIRA, Viviane Almeida; QUADROS, Elton Moreira. Os direitos humanos como efetivação da justiça em Ricoeur e da CERILO, Marcella Marques dos Santos; VIEIRA, Viviane Almeida; QUADROS, Elton Moreira. Os direitos humanos como efetivação da justiça em Ricoeur

Deste modo, a aplicação da justiça por meio das instituições judiciárias advém do ato de julgar praticado pelo juiz, por meio de sua opinião, e por considerar verdadeiro e justo, toma uma posição, a decisão final.

Considerado por Ricoeur nos limites estritos do processo, o exercício do ato de julgar se situa facilmente num funcionamento geral da sociedade, considerada por Rawls, como um vasto sistema de distribuição de partes (RICOEUR, 2008a). É sob a égide da ideia de justiça distributiva que o ato de julgar se deixa representar, de forma a apartar esferas de atividades, delimitar as pretensões de um e as pretensões de outro e, em corrigir as distribuições injustas, quando a atividade de uma parte consiste realmente em estabelecer a parte de um e a parte de outro (RICOEUR, 2008a).

Portanto, Ricoeur considera que o ato de julgar por meio das instituições judiciárias tem como horizonte um equilíbrio frágil entre dois componentes da partilha: "o que aparta minha parte da sua e o que, por outro lado, faz que cada um de nós tome parte na sociedade" (RICOEUR, 2008a, p. 181).

É essa justa distância entre os parceiros defrontados, próximos demais no conflito e distantes demais na ignorância, no ódio e no desprezo, que Ricoeur resume bem os dois aspectos do ato de julgar: "por um lado, deslindar, pôr fim à incerteza, separar as partes; por outro lado, fazer que cada um reconheça a parte que o outro toma na mesma sociedade" (RICOEUR, 2008a, p. 181); em virtude da qual o ganhador e o perdedor do processo seriam considerados como pessoas que tiveram sua justa parte nesse esquema de cooperação que é a sociedade detentora de direitos e igualdades.

Assim, os Direitos Humanos como efetivação da Justiça para Ricoeur se dá a partir de três fundamentos essenciais e importantes: (i) a igualdade, que busca estimar a si mesmo e o outro como igual, sempre a buscar o melhor para si e pensando no outro; (ii) o reconhecimento jurídico, em que o reconhecimento mútuo, como reconhecimento do eu e do nós, passa a ser fundamental no caminho da dignidade humana, o que nos lembra a solicitude, em que nos compadecemos para com o outro e (iii) as instituições justas, abordadas aqui como meio de aplicação dos Direitos Humanos, quando um terceiro, que é imparcial e não interessado nas situações de conflitos, faz a mediação, como forma de aplicar a medida mais justa aos que são iguais.

Portanto, pensar os Direitos Humanos como efetivação da Justiça é de suma importância para vivência dos profissionais do Direito, que podem se utilizar dos fundamentos aqui expostos (igualdade, reconhecimento jurídico e instituições justas), de forma a uni-los com um único objetivo, conforme analisou Ricoeur, que é alcançar a efetivação e aplicação dos DH, uma vez 
CERILO, Marcella Marques dos Santos; VIEIRA, Viviane Almeida; QUADROS, Elton Moreira. Os direitos humanos como efetivação da justiça em Ricoeur e da CERILO, Marcella Marques dos Santos; VIEIRA, Viviane Almeida; QUADROS, Elton Moreira. Os direitos humanos como efetivação da justiça em Ricoeur

que a busca constante pela justiça é de primordial importância para uma aplicação mais efetiva dos direitos humanos.

\section{Conclusão}

O conjunto de valores éticos expostos por Ricoeur em sua "pequena ética" se relaciona também com os direitos humanos no que se refere ao respeito às leis, respeito ao bem público, amor à igualdade e horror aos privilégios, a aceitação da vontade da maioria e o respeito das minorias, tendo como seu horizonte o respeito integral à dignidade humana, e não podemos perder de vista que "em um Estado Democrático de Direito a dignidade humana deve ser vista como um direito inerente à humanidade, devendo sempre ser um objetivo a ser alcançado" (CORRALES; BENTONCINI, 2019, p. 251).

Os fundamentos e as garantias jurídicas de proteção dos direitos humanos são ferramentas indispensáveis e constituem um aspeto fundamental para que os direitos não se tornem meras afirmações retóricas.

Contudo, não cabe somente ao Estado à implementação dos direitos, a sociedade civil organizada também tem um papel importante na luta pela efetivação dos direitos, não só através dos movimentos sociais, sindicatos, associações, conselhos de direitos e centros de defesa e de educação. É a luta pela efetivação dos direitos humanos que vai levar esses direitos no cotidiano das pessoas e vai indicar o alcance que os mesmos vão conseguir numa determinada sociedade.

A questão dos DH, hoje entendida em toda a sua complexidade, aponta para um espaço de utopia, ou melhor, de eu-topia, de bom-lugar; funciona como uma ideia reguladora, um horizonte que nunca poderá ser alcançado, porque está sempre mais além, mas sem o qual não saberíamos nem sequer para onde ir (TOSI, 2004).

Portanto, uma reflexão jusfilosófica da relação de justiça e dos direitos humanos nos leva a considerar, a partir do pensamento de Ricoeur, que, para se chegar a uma efetivação da justiça por meio dos Direitos humanos, fundamental é que se tenha a igualdade como estima de si, o reconhecimento jurídico como estima do outro e as instituições justas como ponto de aplicação dessa justiça almejada.

Essa reflexão acaba por definir socialmente e politicamente as condições históricas e reais, nas quais cada pessoa humana realmente é reconhecida em sua identidade de sujeito capaz, digno de igual estima e de igual respeito, que quer viver com e para os outros em instituições justas, formando, com isso, os princípios basilares para efetivação dos Direito Humanos, segundo a abordagem proposta jus-filosófica ricoueriana. 
CERILO, Marcella Marques dos Santos; VIEIRA, Viviane Almeida; QUADROS, Elton Moreira. Os direitos humanos como efetivação da justiça em Ricoeur e da CERILO, Marcella Marques dos Santos; VIEIRA, Viviane Almeida; QUADROS, Elton Moreira. Os direitos humanos como efetivação da justiça em Ricoeur

\section{Referências}

ABEL, O. Paul Ricoeur a promessa e a regra. São Paulo-SP: Instituto Piaget, 2002.

BRASIL. Constituição da República Federativa do Brasil (1988). Disponível em: www.planalto.gov.br/constituição. Acesso em: 21 nov. 2018.

BILLIER, Jean-Cassien, Aglaé Maryioli. História da filosofia do direito. Tradução de Maurício de Andrade. Barueri-SP: Manole, 2005.

CORRALES, E. L. de L; BENTONCINI, C. O princípio da dignidade da pessoa humana como fundamento da justiça restaurativa a partir do pensamento de immanuel Kant. Revista Direitos Humanos e Democracia, v. 7, n. 14, p. 249-262. Disponível em: https://doi.org/10.21527/2317-5389.2019.14.249-262. Acesso em: 04 maio 2020.

FERREIRA FILHO, Manoel Gonçalves. Curso de direito constitucional. 18. ed. São PauloSP: Saraiva, 1990.

LENZA, P. Direito constitucional esquematizado. 12. ed. rev. atual. e ampl. São Paulo-SP: Saraiva, 2012.

MAGALHÃES. T. C. de. A reflexão de Ricoeur sobre o justo. SíNTESE - Revista de Filosofia: Belo Horizonte-MG, v. 29, n. 93, 2002.

MORA. J. F. Dicionário de Filosofia. Tradução Antônio José Massano e Manuel Palmeirim. Lisboa: Dom Quixote, 1978. Disponível em: http://www.portalconservador.com/livros/JoseFerrater-Mora-Dicionario-de-Filosofia.pdf. Acesso em: 25 jul. 2018.

MORAES, A. de. Direitos humanos fundamentais: Teoria geral, comentários aos arts. $1^{\circ}$ a $5^{\circ}$ da Constituição da República Federativa do Brasil. 9. ed. São Paulo-SP: Atlas, 2011.

MORAES, G. L. Paul Ricoer: uma hermenêutica enriquecida. Último Andar, São Paulo, (13), p. 95-110, dez., 2005. Disponível em:

http://www4.pucsp.br/ultimoandar/download/artigo_paul_ricoeur.pdf. Acesso em: 28 abr., 2020.

MAZZUOLI, Valério de Oliveira. Curso de direito internacional público. 3. ed. São Paulo SP: RT, 2009.

ONU. Declaração Universal dos Direitos Humanos (1948). Disponível em: https://nacoesunidas.org/direitoshumanos/declaracao/. Acesso em: 28 nov. 2018.

PADILHA, R. A. Entre o bom e o legal: Ricoeur e a noção de justiça. 2012. Dissertação (Mestrado em Filosofia) - Universidade Federal de Santa Maria, Santa Maria, 2012. Disponível em: http://www3.ufsm.br/ppgf/uploads/2011/10. Acesso em: 25 jul. 2018.

PENTEADO FILHO, N. S. Direitos humanos: Doutrina e Legislação. 4. ed. rev. atual. Rio de Janeiro: Forense; São Paulo: Método, 2011. 
CERILO, Marcella Marques dos Santos; VIEIRA, Viviane Almeida; QUADROS, Elton Moreira. Os direitos humanos como efetivação da justiça em Ricoeur e da CERILO, Marcella Marques dos Santos; VIEIRA, Viviane Almeida; QUADROS, EIton Moreira. Os direitos humanos como efetivação da justiça em Ricoeur

PINTO, L. N. A tríplice constituição da perspectiva ética de Paul Ricoeur. Synesis, v. 4, n. 2, p. 45-62, dez. 2012. ISSN 1984-6754. Disponível em:

http://seer.ucp.br/seer/index.php/synesis/article/view/196/171. Acesso em: 03 jan. 2018.

QUADROS, E. M. Memória, reconhecimento de si e alteridade no pensamento de Paul

Ricoeur. Tese (Doutorado em Memória). Disponível em:

http://www2.uesb.br/ppg/ppgmls/wp-content/uploads/2017/06/Tese-Elton-Moreira-

Quadros.pdf. Acesso em: 06 nov. 2018.

QUADROS, E. M. Sobre a identidade narrativa e a imputabilidade a partir de Ricoeur.

Revista Quaestio Iuris, Rio de Janeiro, v. 11, n. 01, p. 294-311, 2018. Disponível em: http://www.e-publicacoes.uerj.br/index.php/quaestioiuris/article/view/29033/23311. Acesso em: 06 nov. 2018.

RICOEUR, P. O justo 1: a justiça como regra moral e como instituição. Tradução Ivone C. Benedetti. São Paulo-SP: WMF Martins Fontes, 2008a.

RICOEUR, P. O justo 2: a justiça e verdade e outros estudos. Tradução Ivone C. Benedetti. São Paulo-SP: WMF Martins Fontes, 2008b.

RICOEUR, P. O si-mesmo como outro. Tradução Ivone C. Benedetti. 1. ed. São Paulo-SP: WMF Martins Fontes, 2014.

RICOEUR, P. Entrevista: Paul Ricoeur - O respeito da dignidade por todos. Tradução: Sergio de Souza Salles. Lex Humana, tradução de Sergio de Souza Salles, v. 5, n. 1, p. 183-186, jun., 2013. Disponível em: http://seer.ucp.br/seer/index.php/LexHumana/article/view/371. Acesso em: 26 ago. 2018.

SALLES, S. de S. A dignidade do sujeito dos direito humanos. Conhecimento \& Diversidade, [S.1.], v. 6, n. 11, p. 112-122, jun. 2014. Disponível em: https://revistas.unilasalle.edu.br/index.php/conhecimento_diversidade/article/view/1630. Acesso em: 26 ago. 2018.

SALLES, S. de S. Paul Ricoeur e o paradoxo dos direitos humanos. PERI, v. 6, n. 02, p. 209228, 2014. Disponível em: http://www.nexos.ufsc.br/index.php/peri/article/view/930. Acesso em: 26 ago. 2018.

SALLES, S. de S. Paul Ricoeur: a Declaração Universal dos Direitos Humanos - um novo sopro. Synesis, v. 5, n. 2, p. 211-213, dez. 2013. Disponível em: http://seer.ucp.br/seer/index.php/synesis/article/view/433. Acesso em: 26 ago. 2018.

SALLES, W. F. Paul Ricoeur e a lógica do perdão. HORIZONTE - Revista de Estudos de Teologia e Ciências da Religião, v. 17, n. 52, p. 414-435, 30 abr., 2019. Disponível em http://periodicos.pucminas.br/index.php/horizonte/article/view/P.21755841.2019v17n52p414. Acesso em: 04 maio 2020.

SIMÕES, A. C. Solicitude e respeito ao outro em Paul Ricoeur. 2013. Dissertação (Mestrado em Filosofia) - Universidade Federal de Santa Maria, Santa Maria, 2013. Disponível em: http://repositorio.ufsm.br/handle/1/9121. Acesso em: 17 jun. 2018. 
CERILO, Marcella Marques dos Santos; VIEIRA, Viviane Almeida; QUADROS, Elton Moreira. Os direitos humanos como efetivação da justiça em Ricoeur e da CERILO, Marcella Marques dos Santos; VIEIRA, Viviane Almeida; QUADROS, Elton Moreira. Os direitos humanos como efetivação da justiça em Ricoeur

TOSI, G. História e atualidade dos direitos do homem. In: NEVES, Paulo Sérgio da Costa; RIQUE, Célia D. G.; FREITAS, Fábio F. B. (org.). Polícia e Democracia: desafios à educação em direitos humanos. Recife: Bagaço, 2002.

TOSI, G. Direitos Humanos: história, teoria e prática. João Pessoa-PB: UFPB, 2004. Disponível em: http://www.cchla.ufpb.br/ncdh/wp-content/uploads/2015/08/DireitosHumanos-Historia-Teoria-e-Pratica.pdf. Acesso em: 26 ago. 2018. 